V. 2, n. 3, Set. / dez. 2019

REVISTA ENSINO DE GEOGRAFIA (RECIFE)

\title{
FÓRUNS DIGITAIS COMO FERRAMENTA PEDAGÓGICA DE CONSTRUÇÃO E (RE) SIGNIFICAÇÃO DOS SABERES NO AMBIENTE ESCOLAR
}

\author{
Natália Daniela Soares Sá Britto \\ Doutora em Geografia pela Universidade Federal do Rio Grande do Sul (UFRGS). \\ natalia-geo@hotmail.com \\ ORCID Id: https://orcid.org/0000-0003-3781-7842 \\ Pedro Cipriani Manfroi \\ Pós-Graduado em Metodologia do Ensino de História e Geografia (Uninter - 2012) e em \\ Cooperativismo (Unisinos - 2014). \\ pedro.manfroi@maristas.org.br \\ ORCID Id: https://orcid.org/0000-0003-3781-7842
}

Artigo recebido em 24/04/2019 e aceito em 18/06/2019

\begin{abstract}
RESUMO: O presente artigo trata da relevância do Ambiente Virtual de Aprendizagem (AVA) como ferramenta potencializadora dos processos pedagógicos na modalidade presencial, especialmente no que diz respeito à eficiência do uso dos fóruns digitais como atividade de aprendizagem colaborativa e de gestão do conhecimento. Para isto, apresenta uma experiência de incorporação de novos "tempos e espaços" no ambiente escolar através do AVA como estratégia para o desenvolvimento de habilidades e competências éticas, estéticas e políticas relacionadas à tomada de decisões, formulação de estratégias, interação de saberes, colaboração, planejamento e gestão de problemas. Esta experiência foi realizada junto aos estudantes do $1^{\circ}$ ano do ensino médio do Colégio Marista Pio XII, em Novo Hamburgo (RS), no componente curricular de Geografia, tendo como eixo temático a resolução de situações-problemas relacionadas à eutrofização do ambiente natural.
\end{abstract}

Palavras-Chave: Ambiente Virtual de Aprendizagem; Fórum digital; Geografia; Aprendizagem colaborativa.

\section{DIGITAL FORUMS AS PEDAGOGICAL TOOL ON BUILDING AND (RE)SIGNIFICATION OF KNOWLEDGES IN THE SCHOLAR ENVIROIMENT}

ABSTRACT: This article deals with the relevance of the Virtual Learning Environment (AVA) as a potential tool for pedagogical processes in face-to-face mode, especially regarding the efficiency of using digital forums as a collaborative learning and knowledge management activity. For this, it presents an experience of incorporating new "times and spaces" in the school environment through AVA as a strategy for the development of ethical, aesthetic and political skills and competences related to decision-making, strategy formulation, interaction of knowledge, collaboration, planning and problem management. This experiment was carried out with the students of the 1st year of high school of the Marist College Pio XII, in Novo Hamburgo (RS), in the curriculum component of Geography, whose thematic axis is the resolution of situations-problems related to the eutrophication of the natural environment.

Keywords: Virtual learning environment; Digital Forum; Geography; Collaborative learning 


\section{INTRODUÇÃO}

Neste início de século a dinamização e a sofisticação dos meios de comunicação e informação têm assinalado a configuração de um novo paradigma técnico e econômico pautado no desenvolvimento da ciência e da tecnologia de ampla consecução social. A expressão "aldeia global”, cunhada metaforicamente por McLuhanm no início dos anos 1960, já apontava para os possíveis impactos desta revolução tecnológica não só na escala dos processos produtivos e econômicos globais, mas, especialmente, no seu potencial de ressignificação da cultura, da ação social e da difusão do conhecimento e da informação. Em um tempo em que "tudo se articula em um vasto e complexo todo moderno, modernizante e moderno" (IANNI, 1995), as chamadas Novas Tecnologias de Informação e Comunicação (NTICs) se destacam cada vez mais por seu potencial transformador, simbólico e difusor da globalidade, assumindo assim um importante papel nas formas sociais, sobretudo naquelas relacionadas aos contextos de condução e controle dos processos de ensino e aprendizagem.

Conforme aponta Dowbor (2007) a educação já não pode funcionar "sem se articular com dinâmicas mais amplas que extrapolam a sala de aula”, já que esta se caracteriza como o lócus privilegiado de articulação e construção de "pontes entre o mundo da escola e o universo que nos cerca". Em um mundo onde a fluidez se torna norma, a sala de aula precisa enfrentar o desafio de reorganização do seu espaçotempo, ação sem a qual se arrisca o contínuo devir do processo de ensino-aprendizagem. Assim, a escola precisa estar aberta e preparada para a apropriação e produção destes novos significados na medida em que não são apenas as técnicas de ensino que mudam com as novas tecnologias, mas a própria concepção do ensino, de prática pedagógica e de percepção do espaço e do tempo escolar.

Neste artigo buscamos destacar a relevância do Ambiente Virtual de Aprendizagem (AVA) como ferramenta potencializadora dos processos pedagógicos na modalidade presencial, especialmente no que diz respeito à eficiência do uso dos fóruns digitais como atividade de aprendizagem colaborativa e de gestão do conhecimento. Para isto, apresentamos nossa experiência de incorporação de novos "tempos e espaços" no ambiente escolar através do AVA como estratégia para o desenvolvimento de habilidades e competências éticas, estéticas e políticas relacionadas à tomada de decisões, formulação de estratégias, interação de saberes, colaboração, planejamento e gestão de problemas. Esta experiência foi realizada junto aos estudantes do $1^{\circ}$ ano do ensino médio do Colégio Marista Pio XII, em Novo 
Hamburgo/RS, no componente curricular de Geografia, tendo como eixo temático a resolução de situações-problemas relacionadas à eutrofização do ambiente natural.

\section{DIVERSIDADE DE TEMPOS E ESPAÇOS DA APRENDIZAGEM ESCOLAR: EM BUSCA DA RECIPROCIDADE ENTRE AMBIENTE PRESENCIAL E O AMBIENTE VIRTUAL DE APRENDIZAGEM}

A escola, enquanto forma social predominante de condução e controle dos processos de ensino e aprendizagem na sociedade capitalista, se constituiu diametralmente a um tempo e a um espaço que lhe são peculiares. Tradicionalmente, o tempo da escola se consolidou como o simulacro da maquinaria, reproduzindo no cotidiano da educação escolarizada o ritmo e a velocidade da produção, enquanto o espaço se firmara como o lócus do ordenamento e controle dos corpos disciplinados e eficientes. Em seu conjunto, estas concepções de tempo e espaço, consideradas em função das práticas e processos materiais de reprodução da vida social, refletiram na escola um microcosmo da ordem social que dominara a modernidade. Neste início de século, no entanto, esta escola passa a se situar na linha de transição entre uma realidade pretérita, marcada pela crença absoluta na razão instrumental científica, e as novas demandas advindas da chamada condição pós-moderna, com suas rupturas, imprecisões, liquidez e incredulidades. (HARVEY, 1996; ALTHUSSER, 1980; FOUCALT, 1987).

Frente a esta crise paradigmática, a aproximação entre a escola e as NTICs tem se tornado um campo de experimentação e de novas vivências pedagógicas na medida em que a rapidez dos fluxos de informação, de conhecimento e de pessoas infligem na necessidade de ajustamento da educação à velocidade das transformações do mundo, mesmo quando estas são acompanhadas de imprecisões e incertezas. Nesta esteira, o uso das novas tecnologias vai abrindo caminho para a ressignificação do tempo e do espaço escolar, assim como da concepção da educação, dos saberes e da prática pedagógica.

Dentre estes as novas tecnologias, destacam-se os ambientes virtuais voltados diretamente para a prática educativa, conhecidos como "Ambientes Virtuais de Aprendizagem" (AVA). Segundo Valentini (2005), estes podem ser caracterizado como:

(...) um espaço social, constituindo-se de interações cognitivo-sociais sobre, ou em torno, de um objeto de conhecimento: um lugar na Web, 'cenários onde as pessoas interagem', mediadas pela linguagem da hipermídia, cujos fluxos de comunicação entre os interagentes são possibilitados pela interface gráfica. $\mathrm{O}$ fundamental não é a 
interface em si mesma, mas o que os interagentes fazem com essa interface. Nesse sentido, o plano pedagógico que sustenta a configuração do ambiente é fundamental para que o ambiente possa ser um espaço onde os interagentes se construam como elementos ativos, coautores do processo de aprendizagem. (VALENTINI, 2005, p.19)

O AVA ultrapassa a noção de coleção de páginas da web para se relacionar a um conjunto de ações, estratégias e intervenções de aprendizagem num espaço virtual e organizado de tal forma que "propicie a construção de conceitos, por meio da interação entre alunos, professores e objeto de conhecimento" (VALENTINI, 2005). Portanto, este espaço que é virtual e social ao mesmo tempo, remete a uma ressignificação do espaço e do tempo tradicional da educação escolarizada, rompendo com a lógica dos ambientes fixos e prédeterminados, para expandir a possibilidade de flexibilização dos lugares, dos momentos e da relação entre os sujeitos interagentes no processo de construção significativa da aprendizagem.

De acordo com Bisol (2005, p.21) o rompimento das fronteiras convencionais de tempo, espaço e de senso-percepção, apontam para novos demarcadores sociais que "parecem indicar novos vetores subjetivos no encontro do sujeito com outro sujeito em situação de troca e de aprendizagem". Neste conjunto, caminha-se para um novo paradigma da educação onde a inovação tecnológica aponta para a potencialidade de desenvolvimento de novos recursos pedagógicos, de socialização e de escolarização para além das fronteiras seculares da educação convencional. Segundo Bisol (2005, p.23):

\begin{abstract}
As salas de aula criadas pelas máquinas cerebrais - os ambientes virtuais de aprendizagem - gradativamente parecem constituir respostas adequadas a algumas exigências que a era da informação coloca. E, assim como o relógio acabou por modificar a relação do homem com o tempo - uma mudança no modo como o tempo é percebido e subjetivado -, teremos que pensar na relação ensinanteaprendente nessa nova configuração.
\end{abstract}

Tendo em vista que o espaço e o tempo escolar não são neutros, mas sim escolhas determinadas socialmente, estes também educam e fazem parte da cultura das instituições educativas, onde o desafio docente situa-se em:

[...] constituir a escola num outro tempo, num tempo da 'Atualidade', onde o foco no presente nos faria viver cada momento como um acontecimento, sem pretensões de somar o número de aprendizagens para quantificá-la ao final do ano letivo, onde a vivência do processo educacional fosse prazerosa cotidianamente. A mudança que se requer é no como vivenciamos, os tempos de aprendizagem e pedagógico independentemente do tempo de permanência que temos, alunos e alunas, 
professores e professoras, na escola. 'Um tempo para se pensar juntos', para decidir, coletivamente, o que fazer, como fazer, porque fazer [...] Um tempo [...], que podia 'ser tempo de criação' e não o que se vivia nos últimos anos [...] tempo de repetição (OLIVEIRA, 2009, s/p)

Seguindo este desafio, algumas instituições escolares têm dedicado seus projetos pedagógicos para o fomento de novas experiências e situações de aprendizagem que permitam a (re) significação da escola, dos sujeitos, dos saberes e da prática pedagógica, apoiadas na diversificação do espaçotempo escolar, onde se destaca as estratégias de fomento às NTICS como ferramenta didática para as atividades presenciais e extraclasses. Trata-se, em muitos casos, da necessidade de estender os espaços e tempos da vivência escolar, assim como construir "pontes" entre o mundo social, do trabalho e da escola.

Como estudo de caso, apresentamos a experiência dos colégios e unidades sociais da União Marista do Brasil através da implementação do "Marista Virtual 3.0”, um ambiente virtual de aprendizagem que busca articular uma nova concepção do tempo e do espaço escolar, superando o paradoxo entre a profundidade das mudanças das tecnologias e os procedimentos pedagógicos. Segundo as Matrizes Curriculares da instituição, que definem as intencionalidades dos processos de ensino e aprendizagem, o fundamental no planejamento educacional está na decisão sobre o que ensinar e aprender e as estratégias direcionadas para alcançar este objetivo, o que mobiliza uma diversidade de situações, estratégias, materiais e espaçotempos educativos. Segundo os documentos:

O fundamental no planejamento das aprendizagens implica tomar decisões sobre estratégias, materiais, espaços e tempos que possam abranger e favorecer a diversidade de situações/objetos e os diferentes estilos de ensinar e de aprender. Desenvolver capacidades metacognitivas é uma das finalidades das aprendizagens que almejamos no desenvolvimento e avaliação do projeto educativo do Brasil Marista (UMBRASIL, 2016)

Para mobilizar um projeto educativo que contemple uma visão da escola em sua totalidade, articulando as diferentes dimensões da prática educativa, a transformação no espaçotempo escolar se torna um passo importante para transformações mais profundas nas relações entre sujeitos, saberes e práticas pedagógicas. Tais mudanças incluem não apenas a reorganização da escola e da sala de aula, mas especialmente uma nova relação entre os múltiplos espaços potenciais para a prática educativa. Nesse sentido, o estímulo a conformação de múltiplos espaços e tempos escolares favorece o desenvolvimento de uma 
educação que pode se tornar no instrumento científico e pedagógico de transformação da realidade.

\section{O USO DO FÓRUM DIGITAL: UMA EXPERIÊNCIA PEDAGÓGICA DE GESTÃO DO CONHECIMENTO E DE APRENDIZAGEM COLABORATIVA}

Dentre as diversas ferramentas disponibilizadas pelo AVA, destacam-se os fóruns pedagógicos digitais, caracterizados como salas de aula virtuais que permitem a interlocução entre os interagentes, sendo o processo de aprendizagem baseado na colaboração e gestão do conhecimento. De acordo com Alves (2008) o fórum de discussão pode ser caracterizado como:

\footnotetext{
um sistema de conferências assíncronas, fundamentado em groupware, 'sistema com base computacional que suporta grupo de pessoas engajadas em uma tarefa (ou meta) comum e que oferece uma interface de ambiente compartilhada', ou seja, softwares cujo objetivo é viabilizar a comunicação, colaboração, cooperação e coordenação de atividades em grupo. (ALVES, 2008 p. 24)
}

Como nova experiência espaço-temporal, os fóruns favorecem o estabelecimento das relações sociais, sensoriais e de aprendizagem assincrônicas e extraespaciais, assim como se apresenta como um importante espaço de troca de experiências, reflexões e informações para além dos demarcadores tradicionais da escola. Baseando-se na obra de Reushle (1999), Alves (2008) elenca algumas contribuições dos fóruns nos contextos educacionais:

\footnotetext{
Suscitar discussões diversas, brainstorming, compartilhar compreensões sobre um tema, elucidar concepções errôneas, desenvolver novos conhecimentos de forma colaborativa, etc.; Permitir aos participantes atuar com voz igual e interagir com todos, sem as restrições comuns dos ambientes presenciais, como horário, organização e pessoas que dominam os turnos discursivos.; Gravar todas as discussões, para consultas posteriores.; Acrescentar links de acesso a recursos disponíveis na internet, para elucidar pontos, argumentar, compartilhar informações, etc. ;Ter respostas fundamentadas por pensamentos mais reflexivos e elaborados, dada a assincronia do meio.; Promover pensamento crítico a partir de: a) resoluções de problemas; b) partilha de compreensões; c) negociação de significados; d) argüições sobre as interpretações; etc. ; Reduzir sensações de isolamento e promover formação de grupos ou comunidades. (ALVES, 2008, p.28)
}

De acordo com Alves (2008), esta ferramenta favorece, entre outras, o gerenciamento dos processos de aprendizagem através do estímulo ao protagonismo dos estudantes, que se tornam os responsáveis pela argumentação, interlocução, ampliação do repertório de saberes, além da construção de um pensamento com maior rigor, elaboração e ressignificação através 
da prática dialógica. Numa mediação prática, os fóruns se apresentam como uma importante ferramenta didática para o desenvolvimento de metodologias de aprendizagem colaborativa e cooperativa, cabendo ao professor atuar na "criação de contextos e ambientes adequados para que o aluno possa desenvolver suas habilidades sociais e cognitivas de modo criativo, na interação com outrem” (TORRES, 2015 p.62). De acordo com Torres (015):

\begin{abstract}
A aprendizagem colaborativa e a aprendizagem cooperativa têm sido frequentemente defendidas no meio acadêmico atual, pois se reconhece nessas metodologias o potencial de promover uma aprendizagem mais ativa por meio do estímulo: ao pensamento crítico; ao desenvolvimento de capacidades de interação, negociação de informações e resolução de problemas; ao desenvolvimento da capacidade de autorregulação do processo de ensino-aprendizagem. Essas formas de ensinar e aprender, segundo seus defensores, tornam os alunos mais responsáveis por sua aprendizagem, levando-os a assimilar conceitos e a construir conhecimentos de uma maneira mais autônoma. (TORRES, 2015 p.61)
\end{abstract}

Como estudo de caso, apresentamos nossa experiência de aplicação do fórum digital como estratégia didática e metodológica para o gerenciamento de situações-problemas relacionadas ao tema "eutrofização ambiental", no componente curricular de Geografia, tendo como objetivo o desenvolvimento de habilidades e competências éticas, estéticas e políticas relacionadas à tomada de decisões, formulação de estratégias, interação de saberes, colaboração, planejamento e gestão de problemas.

A Geografia, enquanto componente curricular do ensino médio se apresenta como campo fundamental para o estudo e compreensão da produção e da difusão territorial das tecnologias, da informação e das configurações do trabalho humano sobre o ambiente natural, retomando a relação entre sociedade e natureza e contribuindo eminentemente para a formação de um sujeito crítico e capaz de intervir, de modo responsável, sobre o mundo. Nesse contexto, o uso didático-pedagógico do AVA no componente de Geografia se apresenta como importante aliado na análise, compreensão e proposição de respostas e soluções aos problemas da vida moderna, na medida em que amplia os espaços e os tempos do diálogo, das representações e das ressignificações entre o mundo do trabalho, da vida social e do ambiente escolar.

Em termos metodológicos, nossa experiência com os fóruns digitais esteve amparada no desenvolvimento do tema "Eutrofização Ambiental", tendo como objetivo geral o gerenciamento e aplicação dos conhecimentos geográficos de modo colaborativo e com fins propositivos, sendo esta uma estratégia para a ressignificação da aprendizagem e para o 
fomento de ações colaborativas em sala de aula. Para tanto, nosso plano de trabalho buscou desenvolver os caminhos da dialética do concreto (KOSIK, 2010), partindo de uma totalidade caótica e abstrata (pseudoconcreticidade), em direção à reconstrução da totalidade concreta e ressignificada pelo pensamento crítico, dialógico e colaborativo. Neste intento, nosso plano se desenvolveu através dos seguintes passos: a) aprofundamento teórico e análise de situaçõesproblemas; b) formulação de estratégias de intervenção, exposição dialógica e gerenciamento das proposições; c) reconstrução e ressignificação colaborativa do conhecimento.

Figura 1. Esquema de aprendizagem colaborativa pelo Fórum digital Fonte: Autora, 2018

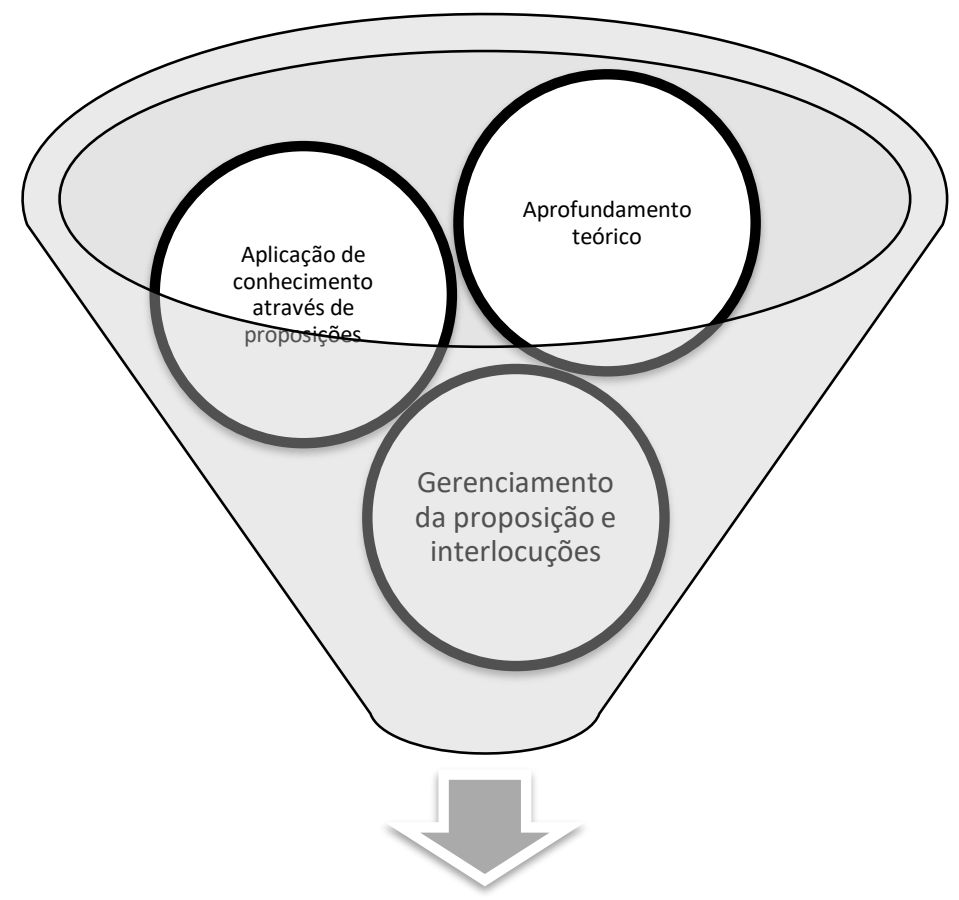

Gestão e ressignificação do conhecimento

Na primeira etapa do trabalho, foram realizadas aulas expositivas dialogadas tratando das teorias e conceitos relacionados à dinâmica geomorfológica e fitogeográfica dos ambientes terrestres, destacando os agentes internos e externos de formação e transformação das paisagens naturais. Nesta etapa, as aulas foram ministradas por meio de exposições teóricas - com o uso de recursos como imagens, vídeos, textos e mapas - acompanhadas de 
discussões sobre as formas, funções, estruturas e processos relacionados aos agentes endógenos e exógenos, em suas múltiplas escalas. Após o aprofundamento teórico foram apresentadas quatro situações-problema, introduzidas por meio de reportagens de abrangência regional e nacional, onde os estudantes receberam como tarefa identificar os fenômenos, os agentes responsáveis, apontar sua constituição e suas (inter) dependências.

Esta etapa, apesar de partir de uma abordagem científica, se configurou como um processo vertical de ensino, onde se fomentou a produção de repertórios ou totalidades "vazias", na medida em que este processo de aprendizagem se limitou aos reflexos superficiais, à determinação dos momentos isolados e à análise abstrata onde o todo foi formalizado face às partes.

Figura 2. Apresentação da situação-problema e formulação de proposições. Fonte: Autora, 2018
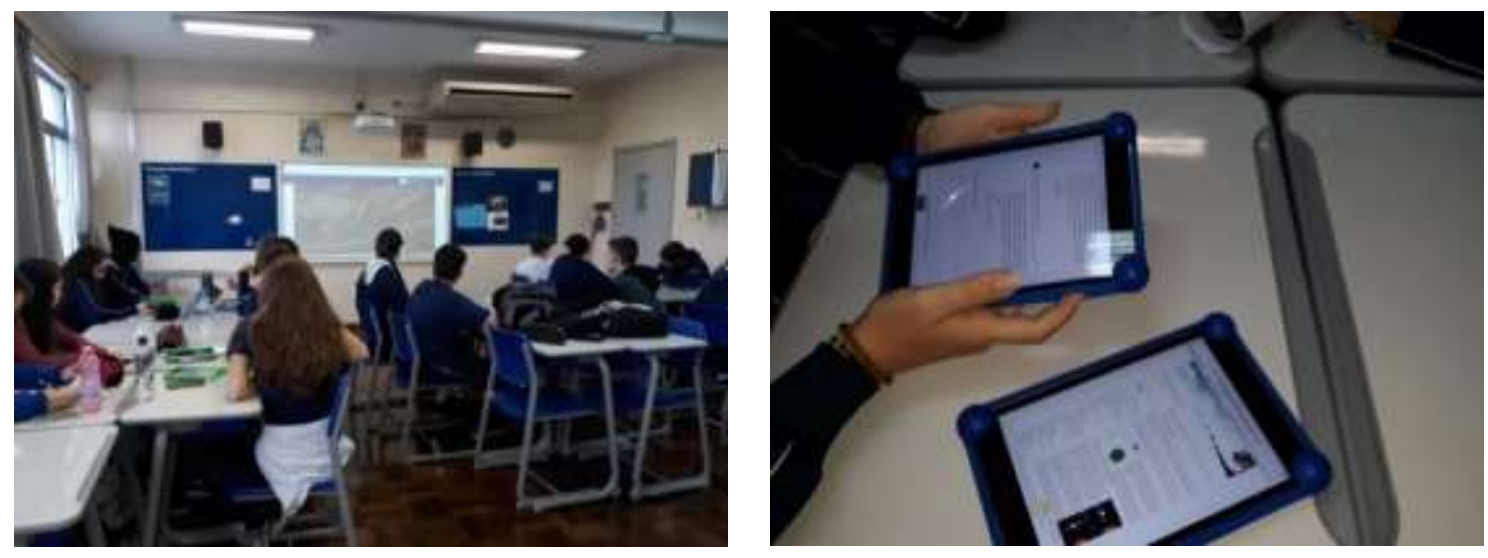

Após a apresentação das situações-problema e sua identificação abstrata, os estudantes, organizados em grupos, iniciaram a formulação de suas proposições através da aplicação dos seus repertórios, ampliando estes saberes através de pesquisas sobre métodos e técnicas para a resolução das problemáticas e sua viabilidade nos casos específicos. Ao promover a construção de um saber de modo colaborativo e cooperativo, os estudantes se tornaram protagonistas do processo de aprendizagem, sendo estes os principais responsáveis por pesquisar as fontes de informação, obter materiais extras, avaliar seus rendimentos e proposições. Ao professor, coube direcionar os momentos de colaboração e de diálogo, avaliando o progresso dos estudantes, alem de auxiliá-los "na busca por fontes de dados confiáveis e na organização das prioridades” (PANITZ 1997, p.23). 
Nesta segunda etapa do trabalho, os grupos compartilharam suas estratégias de intervenção no fórum digital do AVA “Marista Virtual 3.0”, iniciando as interlocuções e o gerenciamento compartilhado das proposições, com o objetivo de ampliar as possibilidades e potencialidades de cada uma destas estratégias. Neste momento, a unidade das contradições e a dialética de fenômeno e da essência, da lei e da casualidade, do todo e da parte se reconstituem, criando um novo significado aos repertórios. Trata-se, agora, do concreto pensado, mediado pela ação dialógica e pelo pensamento crítico, o que confere significação aos saberes construídos.

Figura 3. Compartilhamento, interlocução e gerenciamento das proposições. Fonte: Autora, 2018

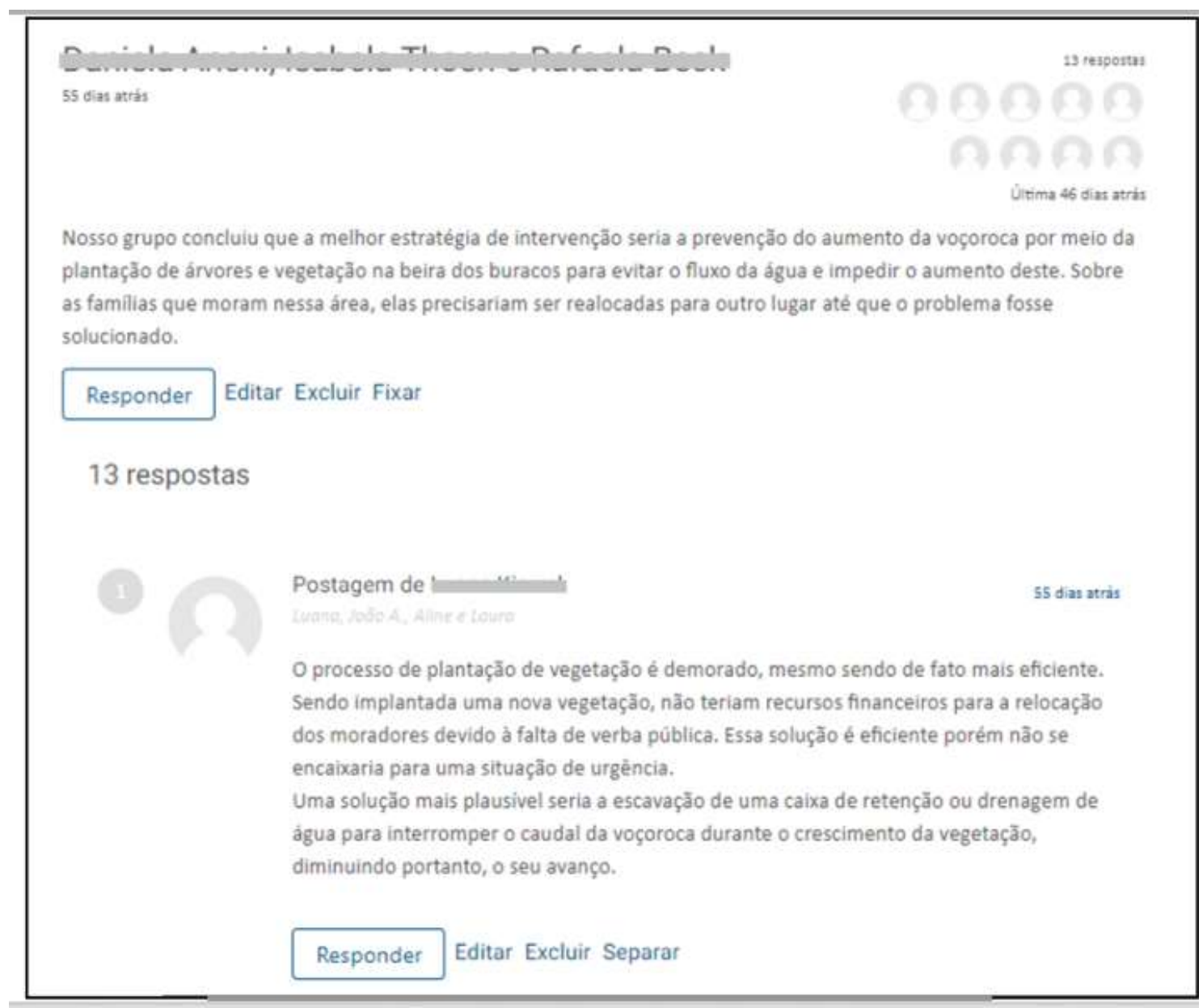

Por fim, na última etapa foram revisitadas as proposições, avaliando os avanços e limites das abordagens expostas no fórum digital do AVA "Marista Virtual 3.0". Neste momento, destacou-se a importância de desenvolver estratégias democráticas para ação na 
realidade social, na medida em que o "conhecimento da realidade, sólidos sistemas de informação, transparência na sua divulgação podem permitir iniciativas inteligentes por parte de todo" (DOWBOR, 2007). De acordo com Dowbor (2007, s/p) esse tipo de decisão, democrática, mas informada, permite o "comportamento inteligente de cada indivíduo, segundo os seus interesses e situação particular, e ao mesmo tempo o interesse comum.”.

Figura 4. Gestão e ressignificação do conhecimento. Fonte: Autora, 2018

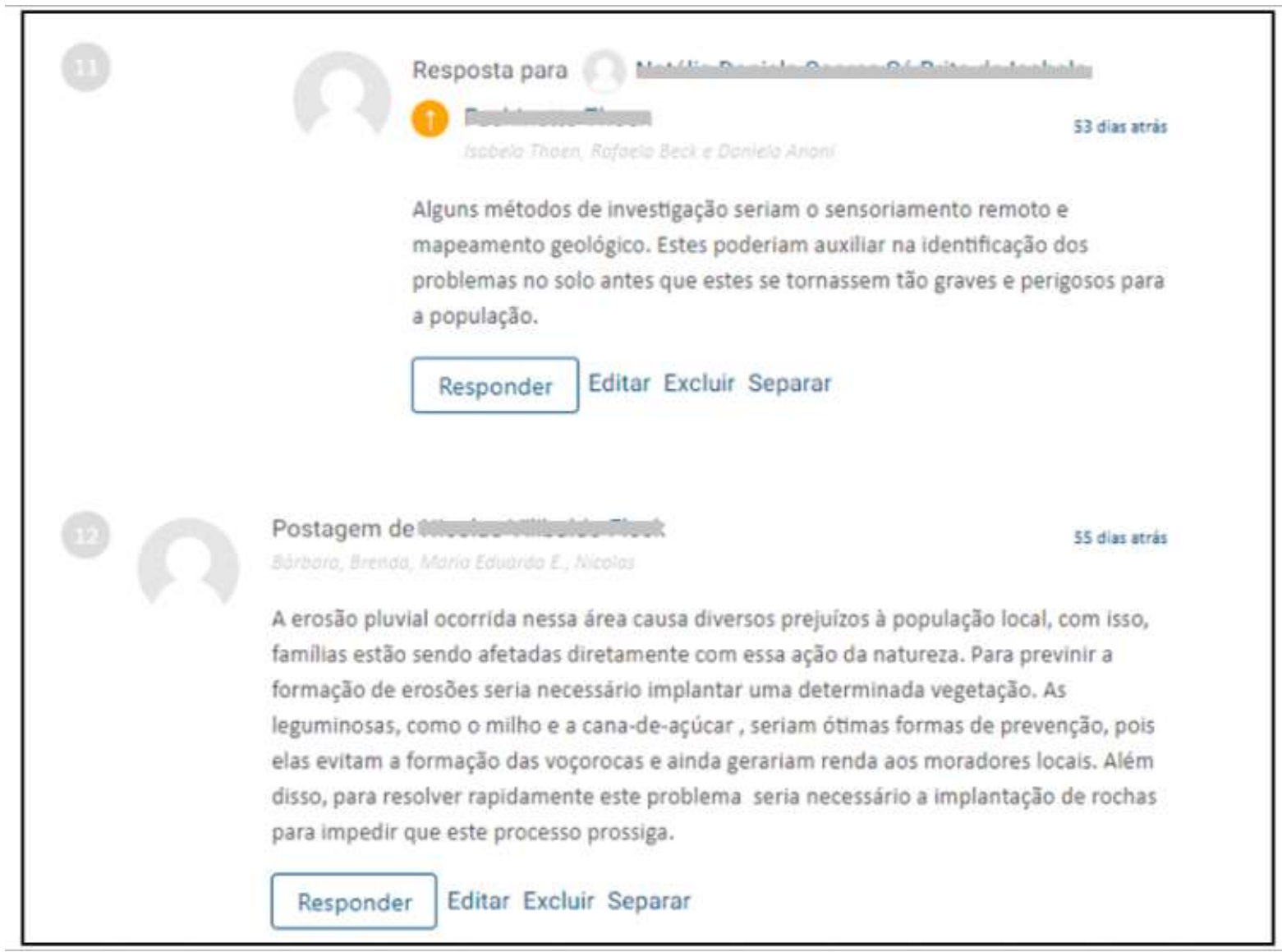

\section{CONSIDERAÇÕES FINAIS}

Frente as novas demandas advindas do mundo pós-moderno, que se realiza cada vez mais associado a um tempo e a um espaço que é comprimido, fluído e flexível, se torna fundamental a apropriação das novas tecnologias pela escola, pois estas potencializam tanto os processos de construção e significação da aprendizagem, como atuam como pontes entre o mundo do trabalho, da vida, da socialização e da escola. Conforme aponta Dowbor (2007), é salutar o rompimento da dicotomia entre tecnologia e ambiente escolar, na medida em que o 
principal paradoxo que enfrentamos na educação escolarizada atualmente se situa no hiato entre a profundidade das mudanças das tecnologias do conhecimento e o pouco que mudaram nossos procedimentos pedagógicos.

Como estudo de caso, apresentamos nossa experiência com o uso dos fóruns digitais do AVA, no componente curricular de Geografia, no ensino médio. O uso do AVA se apresentou como importante ferramenta complementar às aulas presenciais, potencializando a flexibilização e a expansão do espaço e do tempo da sala de aula. Do mesmo modo, as ferramentas disponíveis na plataforma do AVA, como os fóruns digitais, favoreceram o desenvolvimento de atividades didático-pedagógicas voltadas para a aplicação dos saberes e a gestão do conhecimento, ampliando o arcabouço de linguagens, recursos, comunicação, interação e mediação entre os estudantes, de forma colaborativa. Por fim, um dos pontos mais significativo destas estratégias didático-pedagógicas por meio dos ambientes virtuais de aprendizagem encontra-se na potencialidade de fomento ao protagonismo dos estudantes, que se transformam em produtores da informação, mediados pela ação dialógica e pelo pensamento crítico, o que confere significação aos saberes construídos.

\section{REFERÊNCIAS}

ALTHUSSER, L. Ideologia e aparelhos ideológicos do Estado. Lisboa: Presença, 1980.

ALVES, M. Caminhos e entraves para o sucesso de fóruns digitais pedagógicos. Dissertação de Mestrado. Universidade Estadual de Campinas, 2008.

BISOL, C. Ciberespaço: terceiro elemento na relação ensinante/aprendente. In: VALENTINI, C; SOARES, E (Orgs.). Aprendizagem em ambientes virtuais: compartilhando idéias e construindo cenários. Caxias do Sul, RS: Educs, 2005.

DOWBOR, L. Educação e apropriação da realidade local. Revista Estudos avançados. V. 21, n 60, 2007.

FOUCAULT, M. Vigiar e punir: nascimento da prisão. Petrópolis: Vozes, 1987.

HARVEY, D. Condição Pós-Moderna: uma pesquisa sobre as origens da mudança cultural. São Paulo: Loyola, 1996.

IANNI, O. A sociedade global. Rio de Janeiro: Civilização Brasileira, 1995.

KOSIK, K. Dialética do concreto. Rio de Janeiro: Paz e Terra, 2010. 
OLIVEIRA, C. Questões sobre o tempo no espaço escolar. Rio de Janeiro: UFJF, 2009. TORRES, P. Metodologias para a produção do conhecimento: da concepção à prática. Curitiba: SENAR - PR., 2015.

UMBRASIL. Matrizes curriculares de educação Básica do Brasil Marista: área de ciências humanas e suas tecnologias. Curitiba: PUCPRess, 2016.

VALENTINI, C; SOARES, E. (Orgs.). Aprendizagem em ambientes virtuais: compartilhando idéias e construindo cenários. Caxias do Sul: Educs, 2005. 